\title{
Erratum: Vertebroplasty: a point of view on this surgical treatment
}

\section{Saccomanni Bernardino}

Published online: 25 November 2010

(C) Clinical Rheumatology 2010

\section{Erratum to: Clin Rheumatol}

DOI 10.1007/s10067-010-1565-5

This article has been retracted due to plagiarism.

The online version of the original article can be found at http://dx.doi. org/10.1007/s10067-010-1565-5.

S. Bernardino $(\bowtie)$

Department of Orthopaedic and Trauma Surgery,

University of Chieti,

via de Vestini,

Chieti Scalo 66013, Italy

e-mail: bernasacco@yahoo.it 